Research Articles

\title{
Exploring Emotions as a New Quality Parameter in Wine
}

\author{
Miguel A. Pedroza', Robert Herrell ${ }^{1}$ \\ 1 Department of Viticulture and Enology, California State University, Fresno \\ Keywords: tasting, flavor, arousal, pleasantness, emotion, wine, wine quality \\ https://doi.org/10.26813/001c.31663
}

Wine Business Journal

Vol. 5, Issue 1, 2022

Emotions are a fundamental step in sensory evaluation and relate to how consumers make purchase decisions or express preference for specific wine styles. Despite their relevance, it is unclear if emotions can be used as a strategy to evaluate quality and preference in wine. This review aims to define the sensory and physiological processes underlying emotions, revise the current framework to measure emotions in wines, and explore the latest findings linking flavor and marketing actions with emotions and ultimately with wine quality.

\section{Introduction}

A peculiar situation for winery tourists occurs at the moment of entering barrel rooms: guests tend to take a generous sniff from the aroma that emanates from barrels and wine, evoking smiles, surprise, and joyful comments. This type emotional reaction to aromas has been linked to the reasons why consumers get engaged with wine and other foodstuffs. Nevertheless, it is currently unclear how emotions can be measured (Meiselman, 2021) and what is their link to the traditional wine quality attributes such as chemical composition and sensory evaluation.

When tasting wines, consumers are confronted with the often-daunting task of figuring out what they like about it. Color, taste, mouthfeel and aroma will blend simultaneously with contextual factors such as environmental, sociocultural, biological, and psychological factors to create a holistic representation of their experience. The way to measure this complex cascade of sensory stimulation has continuously evolved over the last 80 years and specific methodologies have been developed for different consumers and experts or trained panelists (Lawless \& Heymann, 2010). Consumers are typically tasked with simple questions such as rating wines as function of liking, either with binary (like/dislike) or numerical (7 or 9 point) hedonic scales. On the other hand, experts or trained panelists working in laboratory settings typically use qualitative and/ or quantitative methods to obtain detailed insights about wine sensory attributes (OIV, 2015). For example, the University of California-Davis' 20 points wine scoresheet is a good example of how descriptive analysis breaks down wine quality into visual, aroma, taste, mouthfeel, and finish attributes and allocates quantitative ratings to each of them (Jackson, 2009, p. 235). In order to produce reliable results, descriptive analysis methods require that panelists are extensively trained and regularly tested (Meilgaard et al., 2007), which represents an important logistical and technical challenge.

A significant gap in the literature exists between the methods used to measure sensory attributes in consumers and professionals; consumer methods seem to rely primarily on liking or hedonic ratings which precludes understanding of the sensory attributes behind it (Meilgaard et al., 2015), while expert methods generally focus on descriptive attributes, disregarding or minimizing the subjective nature of hedonic judgements. It is often the case that experts will assign more value to descriptive attributes that are sometimes not consciously noticed or perceived by consumers, such as balance, finish, tannin structure, volume, varietal character. Therefore, a middle point is needed where both hedonic and descriptive aspects are integrated to deepen into the concept of wine quality. A critical question is which methods and parameters can provide this integration? This review aims to highlight the contribution of emotions as a bridge between hedonic, flavor and contextual quality attributes of wines and that they would create a common ground for consumers and experts alike. The following sections will aim to define the physiological processes underlying emotions and current techniques for measuring them. The second part of this review will discuss findings from the literature that describe the use of emotions to characterize wine quality.

\section{Physiological processes behind flavor perception}

Understanding human perception has been an ancestral challenge due to the intricate nature of the sensory organs, the mind, and the wide diversity of stimuli that represent the environment for each individual. Nevertheless, advances in neuroscience and psychology over the last 30 years have contributed tools and techniques to access physiological signals from the brain and different body parts. Techniques such as psychophysiology and functional magnetic resonance imaging are starting to access the human mind and the decision-making processes that define how we react to situations such as deciding whether we like a wine or not (Frost et al., 2015; Parr, 2018; Pazart et al., 2014; Plassmann et al., 2008; Small, 2012).

Once a taster is in contact with wine, the sequence of steps that create a liking decision require that wine stimuli 


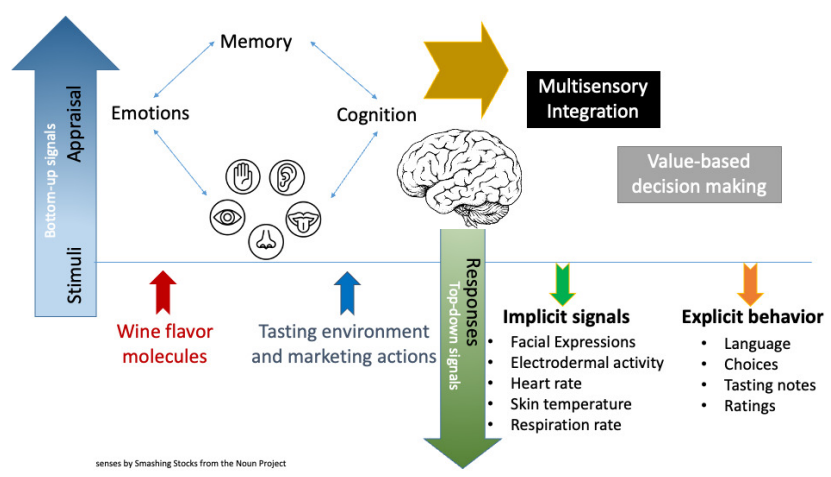

Figure 1.

How wine related stimuli is processed by the brain and types of responses evoked.

originating from smell, taste, or visual attributes are decoded and transformed by specific brain areas. The first part of the process involves the activation of the senses, which operate using sensory neurons and primary brain sensory areas (visual cortex, olfactory bulb, primary olfactory cortex, insula) in charge of detecting the presence of colors, aromas, and taste attributes (De Araujo et al., 2003; Rolls, 2015; Rolls \& Baylis, 1994; Van der Laan et al., 2011) (Figure 1). Next, signaling created by these primary areas will start to flow into secondary and higher order brain areas in charge of emotion, memory, and ultimately cognition (Shepherd, 2015; Small et al., 2012). The evolution from stimulus to the conscious perception in our brains represents the first half in the decision-making process. It is at this appraisal stage that attributes such as valence (pleasantness), arousal (intensity), or saliency (prominence) start being created (Grabenhorst \& Rolls, 2011). At the end of the appraisal stage signals are integrated into a single holistic percept known as flavor (Deco et al., 2013; Shepherd, 2006). Here, higher order brain areas such as the orbitofrontal cortex allow humans to merge information from wine flavor molecules, memories from past experiences, and emotions evoked early during the primary brain processing stage. All these inputs will be combined and weighted to produce responses such as to keep consuming the wine, purchase a bottle, or rejecting a wine due to an unpleasant defect (Kringelbach et al., 2012; Rolls et al., 2008; Shepherd, 2006). This concept is known as value-based decision making (Deco et al., 2013; Grabenhorst \& Rolls, 2011; Shepherd, 2006), and this stage is prone to input from signals other than the wine itself, such as cultural background, prior experiences, social environment, and other aspects that contribute to bias in decision making and notably to the desirability of foods and beverages (Shepherd, 2006).

If a wine has produced a pleasant response, a likely outcome is that the taster will keep approaching the wine by grabbing the glass and taking another sip, writing notes, and using language to describe the different qualities of the sample in turn. On the other hand, if the wine produced an unpleasant response -for example due to an excess of volatile acidity (vinegar aroma and taste)- the taster will likely discard the sample, and verbally ask for a different wine. Both of these reactions require the use of facial muscles to articulate words, and using arm muscles to approach the wine or write a description. These observable actions, or behavior, are the final outcome of the value-based decisionmaking process previously described. In sensory evaluation, behavioral outcomes are typically recorded using explicit measurements such as ratings scales, or the frequency with which tasters preferred a sample (Lawless \& Heymann, 2010). Besides these observable responses, others processes happen "behind the scenes" such as changes in autonomic nervous system signals (ANS) (de Wijk \& Boesveldt, 2016; Kreibig, 2010). For example, tasters will often frown instinctively when confronted with unpleasant or disgusting stimuli (Larsen et al., 2003; Wolf et al., 2005). Bodily reactions from the autonomic nervous system such as frowning (facial expressions), secretion of sweat (electrodermal activity), alteration of the heart rate, changes in skin temperature, and respiration rate can be characterized as implicit measurements, and one of their key features is that they are produced automatically and, in many cases, unconsciously (de Wijk \& Boesveldt, 2016). Moreover, these bodily signals have been proposed as fundamental mechanism that can represent emotional behavior (Kaneko et al., 2018), and constitute an ideal parameter to deepen into how consumers experience wine. Due to the primary role of emotions in defining wine perception and their link to explicit and implicit measurements, the following section will attempt to provide a definition of emotion that can serve as a basis to understand their adoption as wine quality attributes.

\section{Defining Emotions}

Emotions have been defined as a patterned collection of chemical and neuronal responses that are produced by the brain when it detects the presence of an emotionally competent stimulus, such as an object or situation (Damasio, 2001). Perceptual theories posit that emotions carry important information about the world and that "they inform us about our internal physiological and psychological reactions to external events and situations" (Charland, 2014, p. 260) (see Sander, 2013 for discussion). In other words, emotions can be defined as physical signals of the body reacting to external stimuli (Lenzen, 2005). This perceptual approach implies that (1) stimuli - such as wine flavor- are capable of activating internal processes in the body, and (2) the signals evoked can be detected and/or quantified. The interest in characterizing emotions elicited by external stimuli strives from the evidence that they have been linked to affective behavior and decision making involving mood, motivation, drive, desire, preference, attitude, passion, and arousal (Croy et al., 2011; Sander, 2013).

Basic or primary emotions have been proposed from different disciplines, where the terms in table 1 seem to enjoy a more generalized acceptance (Ekman, 1992; Sander, 2013). According to Sander (2013), these terms are constrained by three postulates: (1) they differ one from another in important ways, (2) evolution played an important role in shaping their features and function, and (3) non-basic emotions are made up of blends of basic emotions.

By reviewing the list of basic emotions it is possible to classify the terms into "positive" and "negative" following a valence-based approach; in other words, an emotion would 
Table 1.

\begin{tabular}{|ccc|}
\hline & Primary Emotions & \\
\hline Anger & Fear & Enjoyment \\
\hline Disgust & Sadness & Surprise \\
\hline
\end{tabular}

Primary emotions according to Ekman (1992).

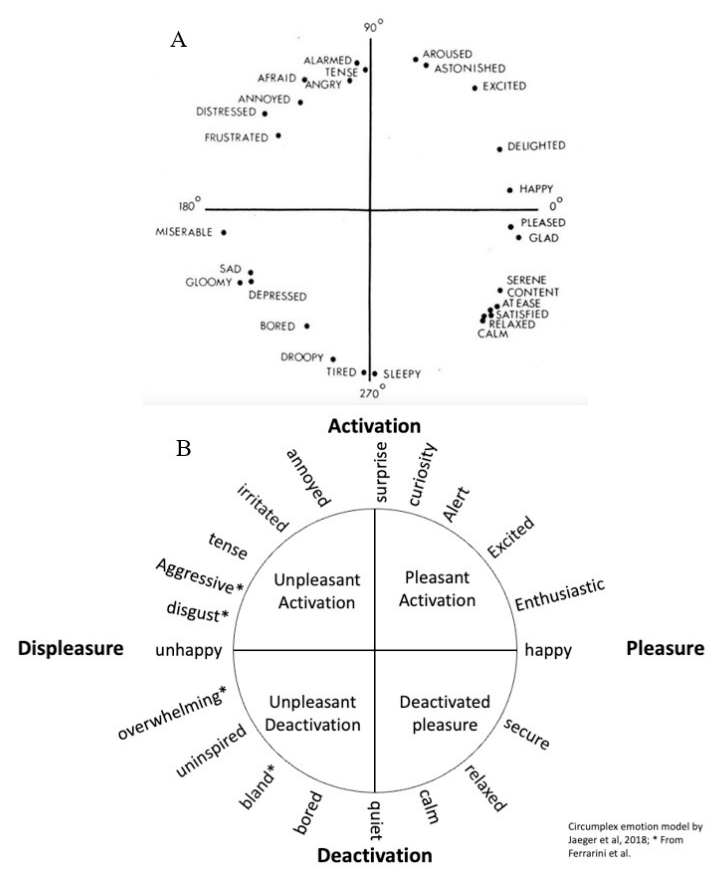

Figure 2.

Circumplex model of emotion from A) Russell, 1980 and B) authors' proposal for wine tasting adapted from Jaeger, Spinelli, et al., 2018 and Ferrarini et al., 2010. Emotional terms are organized along the valence (horizontal) and arousal (vertical) axis.

be classified as positive when "it feels pleasant," or negative when "it feels unpleasant" or even painful (Charland, 2014; Sander, 2013). Besides valence, emotions have been classified according to arousal or alertness, which in emotion literature is described as the pattern of excitation or activation of the sympathetic nervous system over a period of time (Sander, 2013). Valence together with arousal (or intensity) have been considered as the two dimensions that can characterize emotions following the so called circumplex model (Jaeger, Spinelli, et al., 2018; Posner et al., 2005; Russell, 1980). The circumplex model is a two-dimensional space defined by valence and arousal as its principal components that allow to represent discrete emotions in a circular organization (Figure 2). For example, happy can be described as a combination of high pleasantness and slightly elevated arousal (Figure 2).

Beyond primary emotions, secondary terms have been used to describe emotional states in humans. Within the framework of the circumplex model, 28 words were considered to represent different emotions, where half of them are considered positive and the other half is considered as negative (see Figure 2). Notably, this model offers a nearly perfect balanced representation of emotional terms for both the valence and arousal dimensions. Therefore, this approach can be used as a starting point when studying emo- tions in foods and beverages (Jaeger, Spinelli, et al., 2018), in the same way that other disciplines have done (Posner et al., 2005).

One of the main questions in emotions research is how to measure primary or secondary emotions (King et al., 2013; Meiselman, 2021). While self-reported ratings have been widely used in the past, implicit measurements from the autonomic nervous system are currently being explored to study discrete emotions (Kreibig, 2010; Lagast et al., 2017; Meiselman, 2015). In the context of wine consumption, it seems crucial to use both explicit (self-reported ratings) and implicit measurements (physiological reactions) to deepen our understanding of the role of emotions in shaping perceived wine quality.

\section{Techniques for characterizing emotions Explicit measurements of emotion}

The traditional methodologies used to assess perception of food and beverages have primarily used self-reported ratings that use numbers or judgment categories (lexicon) to represent a sensory experience (Lagast et al., 2017). These methodologies are known as explicit measurements and they have been reported as the most commonly used method to measure emotions in foods and beverages (Lagast et al., 2017). The typical sequence of steps to obtain explicit measurements of emotion involves exposing participants to the stimulus, and then recording a rating or choice decision. This approach is based on the ability of each participant to "look into their minds" and use verbal, visual, numerical or graphic methods to capture their conscious representation the emotion evoked by a stimulus (Meiselman, 2021). For example, tasters may choose from a list of words or emojis the ones that best represent the emotion evoked by a sample. When tasters can choose more than one emotional attribute, this method is commonly referred to as "check-all-that-apply" or CATA (Jaeger, Roigard, et al., 2018). Another strategy is to ask participants to assign ratings or place a marking along a continuous line which represents the perceived intensity of the emotion or sensory attribute, commonly referred as rate-all-that-apply or RATA (Ares et al., 2014; Giboreau \& Meiselman, 2018). RATA parallels with traditional tools used in wine tasting, such as descriptive analysis, where multiple sensory attributes are evaluated and quantified according to their intensity by a group of trained tasters (Danner et al., 2018). Descriptive analysis is likely one of the most recurrent and sophisticated explicit measurements used to create flavor profiles. The introduction of emotions into descriptive analysis offers the possibility to increase its power to broaden the characterization of flavor profiles. 
Explicit measurements such as questionnaires and the use of self-reported ratings are characterized by requiring a low to medium degree of training of participants, minimal equipment demands -in its most basic can be administered using pen and paper ballots-, and results can be analyzed by simple nonparametric and parametric statistical tests (Lagast et al., 2017; Lawless \& Heymann, 2010; Meilgaard et al., 2016). Despite their simplicity and ubiquity, explicit measurements are beset by issues that stem from the introspective process that requires participants to first look into their minds and then produce ratings or decisions about the experienced stimuli (Danner et al., 2014; Lawless \& Heymann, 2010). Another issue is the lack of concise references or standards to define emotions and therefore creates the assumption that subjects are proficient in discerning between emotional attributes. Another weakness of explicit methods using scales is that participants will tend to use number differences logarithmically (Lawless, 1989). For instance, the difference between ' 5 ' and ' 10 ' seems larger than the difference between '105' and '110', although it is not. Therefore, the multiplicative difference between these two number sets interferes with our ability to linearly compare them. Another related issue is the idiosyncratic use of numbers; when using scales, tasters will tend to use round numbers such as 5,10, 20, 30, etc. over other numbers (Lawless \& Heymann, 2010). Finally, an important drawback of these techniques is that ratings are usually produced post-stimulation, requiring participants to dedicate attention and memory resources to recreate their perception.

\section{Implicit measurements of emotion}

Implicit measurements of emotion are indirect and nonself-reported responses from different body parts and organs to sensory stimulation (Lagast et al., 2017). Signals from the autonomic nervous system activity including cardiovascular, respiratory and electrodermal measures are amongst the most recurrently used implicit measurements to study emotion related with foods and beverages (de Wijk \& Boesveldt, 2016; Lagast et al., 2017). Considering that experienced emotions involve bodily changes (Neuman \& Adolphs, 2014), these techniques seem particularly suited for providing a window into inner states that are not accessible to questionnaires or ratings, and provide the opportunity to register a continuous response throughout the consumption time frame. Specific implicit measurements linking emotions and sensory stimulation include facial expressions, heart rate, sweat secretion, skin temperature, respiration rate, and neuronal activity (for review see (Lagast et al., 2017). The following section will briefly describe the most prominent body signals currently used to assess both sensory stimuli and emotions.

\section{Electromyography (EMG) and facial expressions}

Facial expressions have been considered as a rich source of information for revealing humans affective states (Van Boxtel, 2010). The fact that facial expressions are modulated by muscular activity makes electromyography and digital image analysis techniques an outstanding tool to evaluate emotions and sensory stimuli. Muscular activity relies on the electrical signal of muscles stimulated by neurons (Stern et al., 2000). As muscle activity increases, it produces a signal susceptible of being measured (typically in micro volts, $\mu \mathrm{V}$ ) with sensors (electrodes). The facial action coding system, first proposed by Ekman and Friesen (Ekman \& Friesen, 1978), correlates specific facial muscle activity with discrete emotions. Within this framework, the corrugator supercilii (above the eye, associated with frowning) and zygomaticus major muscles (in the cheek, associated with smiling) have been used to evaluate the emotional impact of sensory stimuli (Bailey, 2016; Delplanque et al., 2009; Nath et al., 2020; Neta et al., 2009; Sato et al., 2021; Van Boxtel, 2010). For example, corrugator supercilii muscle activity is associated with emotions of fear, anger, sadness, and disgust (Van Boxtel, 2010; Wolf et al., 2005). In relation to aromas, unpleasant odors have been shown to elicit significantly higher activity in corrugator supercilii compared to pleasant ones (Beyts et al., 2017; Delplanque et al., 2009). On the other hand, the zygomaticus major muscle is associated with positive emotions, such as happiness (Van Boxtel, 2010). For example, increased expressions of happiness related to zygomaticus major activity have been reported using digital image analysis software to differentiate between stimuli with positive and negative valence (de Wijk et al., 2014; He et al., 2014). Nevertheless, conflicting results from several studies have shown a significant increase in zygomaticus major activity for both pleasant and unpleasant odors (Beyts et al., 2017; De Wijk et al., 2012; de Wijk et al., 2014), possibly related to smile responses evoked when covering up unpleasant emotions (Ekman et al., 1983).

Decoding emotions from facial expressions via digital images or videos is another technique that has gained momentum for sensory studies. Facial features such the movement of eyes, nose, lips, brows, cheeks, etc. are analyzed using Automated Facial Coding software allowing to identify and, in some cases, quantify experienced emotions (Lewinski et al., 2014; Rajesh \& Naveenkumar, 2016; Stockli et al., 2018; Van Boxtel, 2010). This technique offers the advantage of evaluating basic emotions and additional facial expression measures using only the digital image of the camera as a sensor, instead of using multiple contact electrodes required for EMG.

\section{Electrocardiogram (ECG) and heart rate signals}

The cardiovascular system is integrated by the heart, blood vessels, and the blood itself and its main purpose is to distribute substances required for organs function, support immune responses and facilitate thermoregulation (Aaronson, 1999). The cardiovascular system is powered by repeated muscular contractions of the heart, which are commonly measured by means of an electrocardiogram (ECG) signal and expressed in beats per minute or heart rate (HR). Different types of sensory stimuli are able to elicit changes in heart rate and this parameter has been used to characterize emotional responses (Agrafioti et al., 2012; Bensafi, 2002; Danner et al., 2014; He et al., 2017; Kreibig, 2010; Lacey \& Lacey, 1978; Licon et al., 2018). The intake-rejection hypothesis of cardiac response states that, in general, reduced heart rate allows for more effective neural process- 
ing, such as when an experience is pleasant, and increased heart rate promotes rejection to intense and unpleasant stimuli (Lacey \& Lacey, 1978). Some authors have found that HR decreases 5 - 6 seconds after odorant stimulus, with a more intense decrease for pleasant rather than unpleasant odorants (Delplanque et al., 2009; He, De Wijk, et al., 2016). In other studies, HR has been seen to increase in response to both pleasant and unpleasant odorants, with a higher and quicker increase for unpleasant odorants (Bensafi, 2002; He et al., 2014). Smelling jasmine tea and lavender have been shown to decrease heart rate up to $30 \mathrm{~min}$ utes after exposure (Kuroda et al., 2005), suggesting that the main aroma compounds have a sedative or relaxing effect.

\section{Electrodermal activity (EDA)}

Electrodermal activity refers to the signals that model autonomic changes in the electrical properties of the skin (Braithwaite et al., 2013). The activation of eccrine sweat glands causes sweat to rise to the skin surface, sometimes overflowing and causing a change in skin conductance. This change can be quantified using electrodes (measured in $\mu$ Siemens), and this technique has been widely used to assess arousal linked to emotional and cognitive states (Braithwaite et al., 2013). EDA parameters recurrently studied are the total skin conductance response (SCR), latency between stimulus exposure and reaction, amplitude, signal rise time, and signal recovery time. In the context of food, aromas and pleasantness, EDA responses are characterized by a signal increase for both pleasant and unpleasant stimuli until 3-4 seconds after stimulus, with a higher increase for unpleasant stimuli (Bensafi, 2002; Delplanque et al., 2009; He et al., 2014; He, De Wijk, et al., 2016). After this period, some have reported a further EDA increase for unpleasant aromas and a decrease for pleasant ones (AlaouiIsmaili et al., 1997; de Wijk et al., 2014; He, Boesveldt, et al., 2016). Other authors have reported a quicker signal recovery time for pleasant odors (Delplanque et al., 2009).

A common theme in all physiological parameters is a temporal delay between stimulation and successive physiological events (Alaoui-Ismaili et al., 1997; de Wijk et al., 2014; Delplanque et al., 2009). This is explained by the appraisal theory, which postulates that emotions are the result of sequential appraisals over time, which are then reflected in separate physiological events (De Wijk \& Boesveldt, 2016; Ellsworth \& Scherer, 2003). This sequential appraisal leads to initial physiological responses reflecting arousal or novelty, and later responses reflecting pleasantness of a stimulus.

One of the main advantages of implicit measurements of emotion over their explicit counterparts include the use of non-self-reported parameters that are recorded while participants are experiencing the stimuli, therefore bypassing cognitive bias, memory, and attention demands (de Wijk et al., 2012; Lagast et al., 2017). Moreover, the automatic response of body signals to stimuli also implies that participants are not responsible for thinking about what they feel (intrpsection) and then translate their perceptions into a rating, or identifying the word that best describes their experience. On the other hand, one of the drawbacks of these techniques is the need for specialized equipment and personnel to record and analyze the data. Further, additional time is required for the preparation of participants, and depending on the available technology, cables and sensors need to be attached to different body parts, which may interfere with the sensory experience. It is important to note that the implicit measurements parameters that effectively differentiate between emotions are still under investigation (Kreibig, 2010). The application of implicit measurements for wine related research often requires multidisciplinary collaborations with psychologists, neuroscientists, computer scientists, among others; far from being a drawback, this offers the possibility of broadening the scope of research questions.

\section{Research in wine and emotions}

To explore the application of emotions as a framework to evaluate wine quality, we performed a systematic literature review with the objective to identify the main research questions and methods published since 2010.

\section{Study search and selection}

A similar approach to Kaneko et al. (2018) and Lagast et al. (2017) was followed to search for research papers investigating emotions as a parameter to evaluate wine quality. To be considered in the review, the following inclusion criteria were defined: (1) original articles should be published in English by a peer-review journal (2) the methodology should involve either direct contact with wine, such as seeing, tasting, or smelling wines or indirect representations (such as thinking about wine or seeing images of wines); (3) measurement of emotions should be directly linked or evoked by wine (4) data should be obtained from healthy human populations; (5) the term "emotions" should be a primary focus of the research and be part of either the title, abstract, or keywords; (6) Emotion related terms "mood" and "feeling" were considered to fulfill the inclusion criteria.

\section{Study screening}

Four databases available to the researchers and providing the opportunity to create restriction for full-manuscripts according to the inclusion criteria were used to search for original research papers: ScienceDirect (www.sciencedirect.com), Web of Science (www.webofscience.com), OneSearch (https://csu-fresnostate.primo.exlibrisgroup.com), and PubMed (https://pubmed.ncbi.nlm.nih.gov/). The search was restricted to articles published between January 2010 until the End of June 2021. The search query included the words: "wine" AND (emotion OR mood OR feeling). Further, the search was restricted to papers that had the query terms in their title, abstract, or keywords. As a result, we obtained an initial pool of 695 references from all databases (Figure 3). Within each database we screened the search results by reviewing the title and abstract of each reference and kept the articles that were relevant to our objectives. The pool of selected articles for each database was independently compiled into a reference manager software (EndNote X9, Clari- 


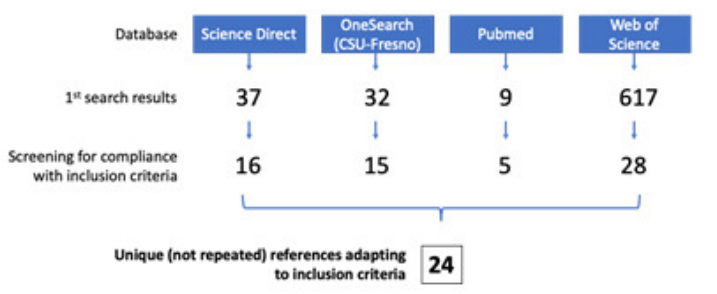

Figure 3.

Schematic representation of the literature search and screening of manuscripts obtained from different databases.

vate Analytics) and then combined into a general list where duplicate references were removed. As a result, we identified 24 research manuscripts that complied with the inclusion criteria. Figure 3 describes the search procedure and the number of references found at each step of the process.

\section{Overview of selected references}

The annotated review of the references allowed to identify four focus areas, namely Lexicon, Context, Winemaking-Wine Flavor, and Taster Profile (Figure 4). The focus areas were defined primarily by the independent variables controlled in the experiments involving the emotions, and by reviewing the aims, objectives, or hypotheses of each manuscript (Table 2). These criteria allowed for a single manuscript to be classified into multiple focus areas (see Table 2).

Manuscripts from the lexicon group characterized for devoting most of the research efforts to the development or adjustment of vocabulary (lists of terms) to describe emotions specifically evoked by wine. Manuscripts from the context group studied how explicit measurements of emotions were influenced by extrinsic variables (not derived from the wine itself) such as room decoration/ambience, consumption occasion, wine label information, winery/regional reputation, and price. The taster profile group characterized for studying the effect of nationality, age, gender, income, degree of wine involvement, and personality. Finally, the winemaking or wine flavor group characterized for involving wine samples from specific regions (appellations of origin, mostly European or Australian), wine styles (red, white, rose, sparkling, sweet, and semi-sweet), spiked

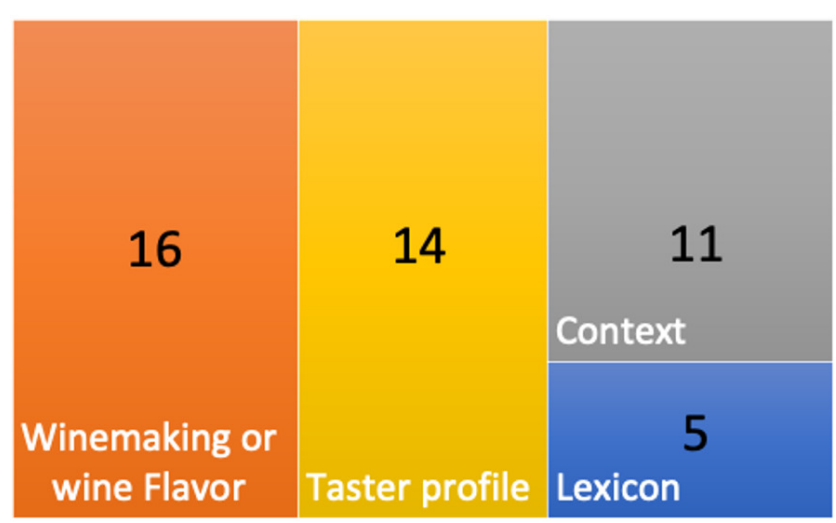

\section{Figure 4.}

Classification and number of peer-reviewed manuscripts according to their main focus areas.

wines (with aromas) or for linking sensory descriptors of flavor (aroma, taste, or mouthfeel) with emotions.

Wine and emotion research has seen a steady pace of publication since 2016, with an average of almost four manuscripts per year (See Table 2). The most recurrent stimuli to evoke emotions included primarily red and white wines, nevertheless several experiments required participants to think about wine or use memories from consuming wine. The papers involving memories allowed researchers to use online survey methods, which facilitated data collection from a significant number of participants (up to 3000 (Ristic et al., 2019)). On the other hand, studies using wine as stimuli had an average of 175 participants, who were primarily consumers. The number of independent variables studied ranged from one to five, and for most studies included demographic or taster profile characteristics. All papers included implicit measurements of emotion such as questionnaires, lexicon paired with check-all-that-apply or rateall-that-apply, and self-reported hedonic ratings. Implicit measurements were only used by one manuscript (Horska et al., 2016) despite of their trending emergence for the evaluation of other foodstuffs (Lagast et al., 2017; Meiselman, 2021). The following sections will aim to present an overview of research highlights from each of the focus areas identified in Figure 4. 
Table 2.

\begin{tabular}{|c|c|c|c|c|c|c|c|c|c|}
\hline \multirow[b]{2}{*}{$\begin{array}{l}\text { First } \\
\text { author }\end{array}$} & \multirow[b]{2}{*}{ Year } & \multicolumn{4}{|c|}{ Classification by focus area } & \multirow[b]{2}{*}{ Wine Stimuli type } & \multirow[b]{2}{*}{ Participants } & \multirow[b]{2}{*}{ Explicit measurement } & \multirow[b]{2}{*}{$\begin{array}{c}\text { Number } \\
\text { of } \\
\text { Emotions }\end{array}$} \\
\hline & & Lexicon & $\begin{array}{l}\text { Winemaking } \\
\text { or wine } \\
\text { flavor }\end{array}$ & Context & $\begin{array}{l}\text { Taster } \\
\text { profile }\end{array}$ & & & & \\
\hline $\begin{array}{l}\text { R. } \\
\text { Ferrarini }\end{array}$ & 2010 & 1 & 0 & 0 & 1 & Memory & 278 & Lexicon ratings of suitability & 16 \\
\hline $\begin{array}{c}\text { C. } \\
\text { Porcherot }\end{array}$ & 2015 & 0 & 1 & 1 & 1 & Kir (white wine + fruit liquor) & 280 & $\begin{array}{l}\text { ScentMove }{ }^{\circledR} \text { questionnaire; } \\
\text { VAMS questionnaire }\end{array}$ & 6 \\
\hline L. Danner & 2016 & 1 & 1 & 1 & 1 & Shiraz red wine & 349 & Lexicon (AWEEL) & 20 \\
\hline E. Horska & 2016 & 0 & 1 & 0 & 0 & Pinot Gris & 22 & Scaling & 6 \\
\hline $\begin{array}{c}\text { V. } \\
\text { Loureiro }\end{array}$ & 2016 & 0 & 1 & 0 & 0 & $\begin{array}{l}\text { White and red wines ( } 40) \text { from multiple } \\
\text { regions and countries }\end{array}$ & 32 & $\begin{array}{l}\text { Modified OIV-tasting sheet } \\
\text { ratings including emotions by } \\
\text { sensory modality }\end{array}$ & na \\
\hline A.P. Silva & 2016 & 0 & 1 & 1 & 1 & Beer, Wine, non-alcohol-beer & 56 & $\begin{array}{l}\text { Interviews, frequency of term } \\
\text { categorization }\end{array}$ & 25 \\
\hline L. Danner & 2017 & 0 & 1 & 1 & 1 & White wines $(\mathrm{CH}, \mathrm{RI}, \mathrm{SB})$ & 126 & liking, AWEEL, WTP & 19 \\
\hline W. Jiang & 2017 & 0 & 1 & 1 & 1 & red wine CS, spiked with aromas & 105 & Liking, Emotions from lexicon & 19 \\
\hline J. Niimi & 2017 & 0 & 1 & 0 & 1 & white wines (Semillon) & 112 & Liking, Emotions from AWEEL & 19 \\
\hline $\begin{array}{l}\text { C. Calvo- } \\
\text { Porral }\end{array}$ & 2018 & 0 & 0 & 1 & 1 & $\begin{array}{l}\text { Wine (not specified); in a restaurant } \\
\text { setting }\end{array}$ & 570 & $\begin{array}{l}\text { Questionnaire; RATA of } \\
\text { emotions lexicon ratings from } \\
\text { Ferrarini et al. } 2010\end{array}$ & 16 \\
\hline A. Coste & 2018 & 0 & 1 & 0 & 1 & Dry red wines & 103 & $\begin{array}{l}\text { Sensory and emotional } \\
\text { descriptors CATA }\end{array}$ & 25 \\
\hline $\begin{array}{l}\text { S. R. } \\
\text { Jaeger }\end{array}$ & 2018 & 0 & 0 & 0 & 1 & $\begin{array}{l}\text { Memory: Written description of red } \\
\text { wine consumption situation }\end{array}$ & 450 & $\begin{array}{l}\text { Emoji questionnaires-CATA, } \\
\text { online survey }\end{array}$ & 40 \\
\hline M. Mora & 2018 & 1 & 1 & 0 & 1 & Red (3) white (2), rose (1) & 208 & $\begin{array}{l}\text { Liking, emotion lexicon } \\
\quad \text { (EsSense25) }\end{array}$ & 25 \\
\hline A. P. Silva & 2018 & 0 & 1 & 0 & 0 & $\begin{array}{l}\text { White wines (2), with and without oak } \\
\text { ageing }\end{array}$ & 69 & $\begin{array}{l}\text { Temporal dominance of } \\
\text { sensations (TDE), emotions } \\
\text { (TDE), Temporal Liking (TL) }\end{array}$ & 10 \\
\hline $\begin{array}{l}\text { C. Calvo- } \\
\text { Porral }\end{array}$ & 2019 & 0 & 0 & 0 & 1 & $\mathrm{n} / \mathrm{a}$ & 462 & $\begin{array}{l}\text { Survey of emotions and } \\
\text { satisfaction }\end{array}$ & \\
\hline M. Mora & 2019 & 0 & 1 & 0 & 1 & Red (3) white (2), rose (1) & 175 & $\begin{array}{l}\text { Liking, emotion lexicon } \\
\quad \text { (EsSense25) }\end{array}$ & 25 \\
\hline R. Ristic & 2019 & 0 & 1 & 1 & 1 & Memory, 59 aromas & 3000 & $\begin{array}{l}\text { Online survey, hedonic ratings, } \\
\text { ScentMove }{ }^{\mathrm{TM}} \text { scale }\end{array}$ & 18 \\
\hline
\end{tabular}




\begin{tabular}{|c|c|c|c|c|c|c|c|c|c|}
\hline \multirow[b]{2}{*}{$\begin{array}{l}\text { C. Calvo- } \\
\text { Porral }\end{array}$} & \multirow[b]{2}{*}{2020} & \multicolumn{4}{|c|}{ Classification by focus area } & \multirow[b]{2}{*}{ Memory } & \multirow[b]{2}{*}{1269} & \multirow[b]{2}{*}{ Lexicon } & \multirow[b]{2}{*}{16} \\
\hline & & 0 & 0 & 0 & 1 & & & & \\
\hline L. Danner & 2020 & 0 & 1 & 1 & 1 & $\begin{array}{l}\text { Red wines (12, Shiraz) of different } \\
\text { quality }\end{array}$ & 468 & liking, AWEEL, WTP & 19 \\
\hline M. Mora & 2020 & 1 & 0 & 0 & 0 & $\begin{array}{c}\text { Red, rose, white, sparkling, rose, sweet, } \\
\text { semi-sweet }\end{array}$ & 185 & Liking; Emotion ratings & 15 \\
\hline G. Coppin & 2021 & 1 & 0 & 1 & 1 & Red wine (4), White wine (4); European & 126 & Lexicon organized in 5 groups. & 34 \\
\hline M. Kustos & 2021 & 0 & 1 & 1 & 0 & $\begin{array}{l}\text { Red wine (4), Shiraz; Food dishes (4), } \\
\text { information (wine origin), pairing items, } \\
\text { consumption moment }\end{array}$ & 151 & $\begin{array}{l}\text { Liking, AWEEL, pairing rating, } \\
\text { dominance, WTP }\end{array}$ & 19 \\
\hline M. Mora & 2021 & 0 & 1 & 0 & 1 & Red wine (12) & 96 & Lexicon, Liking, & 15 \\
\hline F. Sinesio & 2021 & 0 & 1 & 1 & 0 & Red wine (4), DOC Chianti & 108 & $\begin{array}{l}\text { Lexicon-RATA, Liking, } \\
\text { consumption intention, sensory } \\
\text { attribute RATA }\end{array}$ & 16 \\
\hline
\end{tabular}

Classification of research manuscripts obtained from the systematic literature review. 


\section{Development of emotion lexicons specific for wines}

One of the primary approaches to study emotions in wine and other stimuli has been the use of words or specific vocabulary to represent these complex internal states. Ferrarini et al. (2010) were among the first to develop a specific emotional lexicon to describe wine consumption for a specific population (Italian tasters). Their final list included 16 emotion terms classified into pleasant (12) and unpleasant (4) adjectives (in Italian). One of their main findings was that tasters used more emotional words related with pleasantness to describe the experience of drinking wine. Here, words such as amusing, happy, euphoric, joyful, keen, and passionate amongst the most recurrently used. Another important finding was that emotional terms could be further grouped using arousal (or intensity) into high arousal, lowmedium arousal, and unpleasant emotions. This analysis is in close agreement with the circumplex model of emotion where different terms can be mapped using pleasantness (positive and negative terms) and arousal as the two main axes (Russell, 1980). The authors concluded that integrating emotions in conjunction with taste, olfactory, and visual attributes could be a way to better understand pleasantness evoked by wine (Ferrarini et al., 2010). This approach would be particularly beneficial when studying consumers, who are typically more comfortable using emotional adjectives and lack the training to describe wine using flavor descriptors. An important limitation in this study was that the panelists were not tasting wine at the time when they were choosing the adjectives, and instead were required to build on their past experiences or memories. Moreover, it is likely that their memories came mainly from pleasant experiences, therefore biasing the selection of terms (Desmet \& Schifferstein, 2008; Walker et al., 2003), and explaining the high proportion of positive emotions. Further, participants were not instructed to think about both good and bad wines, which could have provided more comprehensive lexicon. Regardless of these limitations, the manuscript of Ferrarini et al. (2010) has inspired many works on wine and emotion, and its contribution to the field is significant. The seminal contribution of the EsSense Profile ${ }^{\mathrm{TM}}$ lexicon by King \& Meiselman (2010) has also served as a starting point for many research efforts in wine and other foods.

Wine emotion lexicons have been developed by five studies (Calvo-Porral et al., 2020; Coppin et al., 2021; Danner et al., 2016; Mora et al., 2018, 2020), which incorporated different methodological approaches than Ferrarini et al. (2010), and notably, included the tasting of real wine samples. Mora et al. (2020) introduced the Grouping of Irrelevant Terms and a rapid sorting method to generate and validate a lexicon that was successfully applied to classify the emotional profile of different wine styles. Calvo-Porral et al. (2020) substituted the rate-all-that-apply approach (using isolated terms) for full phrases like "I feel happy" to provide a clearer indication of the emotional state to the tasters. To develop a lexicon for Swiss consumers, Coppin et al. (2021) first used emotion terms from existing literature, screen for relevance using a consumer group, and organized the terms into five groups using the Napping method. Taken together, the methodology developed over the last five years has pro- vided streamlined methods to create lexicons for specific populations.

Table 3 presents a compilation of the 72 unique terms (not repeated) used to describe emotions evoked by wine from these studies. Terms were clustered according to the reported valence or arbitrarily based on similarity with other studies. Neutral/ambiguous terms were arbitrarily classified by the authors. The length of wine emotion lexicons within each study ranged from 16 to 34 terms, which were obtained from regional populations. While some degree of overlapping between populations exist, it is evident that different cultures have specific emotional expressions to describe wines. For example, wild, loving, and active were terms only used by Spanish tasters (Mora et al., 2018). Conversely, passionate was an emotion term used by Australian, Italian, Swiss, and Spanish tasters. Notably, the emotional terms presented in table 3 have been obtained from predominantly Caucasian populations, and multicultural approaches would be beneficial to have a broader view of emotions evoked by wine in different cultures. Finally, it is important to note that there is majority of positive valence terms found across studies. This is explained by the hedonic asymmetry caused by the "positive affective disposition towards eating and tasting food" (Desmet \& Schifferstein, 2008; King \& Meiselman, 2010). A recurrent aspect of lexicon development studies is that participants have to select the pertinent emotion terms post-consumption, and have to rely on their memory while screening the list of options, which may range from 6 to 40 terms (average of $19.2 \pm 7.8$ ) according to Table 2. This demanding task calls for optimizing the number of options (Jaeger, Spinelli, et al., 2018; King et al., 2013). For wine studies, this challenge could be addressed by selecting or refining the number of attributes from previously established lexicons such as the one from Ferrarini et al. (2010). Further, complete and balanced coverage of the four circumplex model segments would be advisable (see Figure 2). This could help to establish the relationship between specific flavor attributes and emotions. Notably, little is known about the emotions evoked by wine faults such as reduction, moldy aroma, volatile acidity, animal character, etc.

\section{Effect of contextual variables on emotions evoked by wines}

Within the framework of this review, contextual variables were defined as extrinsic wine attributes that are related to the consumption environment. In this sense, contextual variables may involve visual stimuli such as room decorations or consumption location, and cognitive stimuli such as information, social interactions, moments (occasion) of consumption, and marketing actions. Marketing actions such as information displayed on wine labels or prices are known as factors that can influence consumer behavior in terms of purchase intention and willingness to pay price (WTP) and perceived quality. The seminal paper from Plassmann et al. (2008) was among the first to provide physiological evidence of how marketing actions -the price tag of wine- can have a notorious effect on experienced pleasantness. Remarkably, the authors used functional magnetic resonance imaging (an implicit measurement) to demon- 
Table 3.

\begin{tabular}{|c|c|c|c|}
\hline \multicolumn{2}{|c|}{ Positive } & \multirow{2}{*}{$\frac{\text { Neutral/ambiguous }}{\text { daring }}$} & \multirow{2}{*}{$\begin{array}{c}\text { Negative } \\
\text { aggressive }\end{array}$} \\
\hline active & happy & & \\
\hline adventurous & harmonious & light & bland \\
\hline amazed & impressed & light (soft) & bored \\
\hline amusing & interested & mild & disappointed \\
\hline appetizing & joyful & nostalgic & disgusting \\
\hline astonished & keen & surprised & embarrassed \\
\hline calm & loving & understanding & envious \\
\hline contented & optimistic & warm & guilty \\
\hline curious & over the moon & & irritated \\
\hline delighted & passionate & & lonely \\
\hline desirable & peaceable & & overwhelming \\
\hline elegant & pleasant & & panicky \\
\hline enthralling & pleasantly surprised & & sad \\
\hline enthusiastic & pleasurable & & superior to others \\
\hline entire & relaxed & & tame \\
\hline euphoric & satisfied & & tense \\
\hline free & secure & & unfulfilled \\
\hline fulfilled & sensual & & unpleasant \\
\hline full of hope & tender & & unpleasantly surprised \\
\hline funny & warm-hearted & & worried \\
\hline good & well-being & & \\
\hline good natured & wild & & \\
\hline
\end{tabular}

Compilation of 72 unique emotional terms used to describe wines by manuscripts having a primary focus on lexicon development (Calvo-Porral et al., 2020; Coppin et al., 2021; Danner et al., 2016; Ferrarini et al., 2010; Mora et al., 2018).

strate how activity in brain areas related to decision making and multisensory integration were involved in modulating experienced pleasantness, just by changing the price of the same wine. At the behavioral level, the authors found that liking ratings decreased significantly (approx. 25\% from the rating scale) when a commercial wine originally priced at $\$ 90$ was presented with a price of $\$ 10$. Notably, a similar result in the opposite direction was also observed when a wine originally priced at $\$ 5$ and later presented with a fictitious price of $\$ 45$ saw an increase of liking ratings of approximately $16 \%$. The authors demonstrated that higher order brain regions responsible for multisensory integration, such as the orbitofrontal cortex, together with regions known to process emotions as the amygdala were responsible for changes in experienced pleasantness. These brain regions have also been highlighted as hubs for integrating flavor stimuli, cognitive information, memories of past experiences and internal states among others into decision variables that are used by humans to make decisions (De Martino et al., 2006; Gold \& Shadlen, 2007; Grabenhorst et al., 2007; Hutcherson et al., 2012; Kringelbach, 2005; Kringelbach et al., 2012; Rolls, 2015; Shepherd, 2015; Spence, 2015). The authors concluded that any action capable of creating expectations about product quality would be able of modulating experienced pleasantness (Plassmann et al., 2008).

The information typically displayed in wine labels, such as wine origin, vintage, brand, and price, is one of the pri- mary marketing actions used by the manuscripts in the context group from Table 2. Danner et al. (2017) evaluated how the level of detail shown in a wine label was able to evoke emotions and influence pleasantness. Their experiment focused on white wines from Chardonnay, Riesling, and Sauvignon Blanc and results indicate that emotions were significantly affected by the level of information shown on the labels. Specifically, providing tasters with elaborate information-featuring flavor descriptors, winery history, tradition, and remarks of "high quality"-was shown to evoke more intense positive emotions and less intense negative emotions compared to labels with basic sensory descriptors or when tasting the wines without any information. Willingness to pay and perceived quality also increased by providing more elaborate information compared to basic sensory description and blind tasting. In agreement with these findings, Kustos et al. (2021) found that providing wine origin information created expectations in consumers, which could evoke positive emotions if expectations were met, and negative emotions when expectations were not met. Specifically, providing information about wine origin prompted more intense positive emotions of warm hearted, optimism, passionate, and positive surprise in a wine and food consumption scenario, whereas negative emotions of panicky, sad, irritated, lonely and envious had higher ratings in a "blind" condition without wine origin information (Kustos et al., 2021). Conversely wine reputation, price, and label did not produce a significant main effect in 
the number of emotions elicited by the wines in a study with Swiss consumers evaluating eight different wines (Coppin et al., 2021). This disagreement suggests that the level of information typically found in labels affects differently consumers from multiple nationalities, and reinforce the need to consider the occasion of consumption and, notably, the taster profiles (demographics, product engagement) when assessing emotions evoked by wine.

The effect of consumption occasion and environment on emotions evoked by different wines were two of the main variables studied within the context group in Table 2 . Occasions for consuming wine included restaurants or "dining out", home, parties, barbecues, pubs/bars, and other social events, besides laboratory environments which represented a control condition.

Consuming wine in restaurants and social environments was found to produce higher ratings for positive emotions such as calm, contented, enthusiastic, happy, and relaxed compared to a laboratory testing context (Danner et al., 2020). Moreover, consumers' level of wine involvement had an interaction with the environment, where wine enthusiasts experienced more intense positive emotions and liking of wines in restaurants and laboratory conditions compared to tasters with lesser wine engagement (Danner et al., 2020). A link between consumption occasion, sensory descriptors, and emotions evoked by wines was established by Ristic et al. (2019). The authors found that wines with lemon aroma were associated with energetic (positive and high arousal) feelings and preferably consumed at parties and BBQ in the summer (Ristic et al., 2019). Wines with "chocolate" aroma were found to evoke more romantic feelings and preferably consumed in restaurants, whereas "passionfruit" aromas were associated with happiness and consumed anytime regardless of the occasion (Ristic et al. 2019). Using structural equation modeling, Calvo-Porral et al. (2018) concluded that "occasion of consumption contributes to modify and shape the emotional experience in product consumption”. Drinking wine has also been used to celebrate and extend moments (Silva et al., 2016), which highlights a correlation with positive emotions. Further, Silva et al. (2016) highlighted the tendency to consume wine with meals (at dinner and lunch), at home, parties, restaurants, and in the company of family and friends. One question that emerges from these findings is how to disentangle the contribution of context and wine to experienced emotions. In this sense, Sinesio et al. (2021) found that context more than wines influenced the rating of emotions and sensory terms. In their study, participants tended to provide lower scores when tasting wines at home compared to a laboratory or a social situation such as a party or restaurant (Sinesio et al., 2021). Moreover, specific emotions such as happy and euphoric evoked by consuming wine were rated higher in a social context (Sinesio et al., 2021). Future studies are likely to expand our understanding of consumption occasions by comparing neutral tasting conditions (sensory laboratory) against real life scenarios and real wine samples with specific flavors (aromas, taste, mouthfeel).

Experiential shopping, defined as "the act of purchase of services and goods stimulated by the combined, in store and environmental sensory stimuli", has been suggested to elicit emotions in specific consumer populations (Cabiddu,
2007, p. 151). This approach posits that consumers are always looking for pleasurable experiences, which are linked to positive emotions (Santisi \& Platania, 2014). Spatial and social dimensions of experiential shopping are tangible and intangible environmental aspects that can be inside a store such as such as packaging, store atmosphere, music, lighting, and aromas; social dimensions are "direct and indirect relationships that are established between the various parties -consumer-producer-retailer, to name the main components- at the place of purchase” (Platania et al., 2016). Therefore, wine purchase decisions by consumers involve product-related aspects (wine flavor, label, price, etc.), and purchase experience. Given the complexity of combining these factors in value-based decision making (Grabenhorst \& Rolls, 2011), consumers tend to adopt risk aversive strategies to minimize the likelihood of choosing a "bad wine" or a wine that is below their expectations (Combris et al., 2009; Platania et al., 2016). In this sense, Platania et al. (2016) found a significant correlation between emotional states, wine store environment, and purchase behavior in 130 Italian consumers. The authors also found that women (73 percent of sample population) were more influenced by store environment than men. While methodological details about discrete emotions were missing, these results highlight the positive correlation between positive emotions, favorable store environment, and purchase decisions (Platania et al., 2016). The influence of spatial dimensions such as room decorations on emotions evoked by consuming wine have also been studied by Jiang et al. (2017). The authors compared a "floral room"-featuring orange table cloths, chairs, and fresh odorless flower arangements-with a "green room" decorated with green table cloths and chairs, potted plants, and a projection of the image of a forest landscape. Opposite to Platania et al. (2016), room decoration or immersive space did not produce a change in hedonic ratings or emotions (Jiang et al., 2017). This result was attributed to the lack of explicit instructions to immerse or imagining being into the contextual themes (floral and green). Moreover, the authors indicated that the sensory task design required participants to first complete the descriptive flavor analysis and then the emotion questions. It is likely that the time delay between tasting the wine and completing the questionnaire was one of the factors behind the lack of differences, although it is unclear if participants were able to retaste the samples ad libitum.

The growing evidence of how contextual variables may be able to evoke specific emotions and influence hedonic attributes suggests that this topic is likely to stimulate more research in the field. Nevertheless, contrasting results from the different studies reviewed so far indicate that some effects might be dependent on the population under study, which will be addressed in the following section.

\section{Taster profile according to emotions evoked by wine}

Taster profile studies linking emotions and wine have primarily focused on the effect of product involvement, nationality, demographics (age, gender), and personality of consumers (see Table 2). Product involvement studies were characterized by the classification of participants according 
to their level of wine consumption frequency, wine knowledge, and wine appreciation (Calvo-Porral et al., 2018, 2019, 2020; Coppin et al., 2021; Danner et al., 2020; Jaeger, Lee, et al., 2018).

Calvo-Porral et al. (2020) remarked that "the average consumer does not exist" and hypothesized that emotional descriptors evoked by tasting wines could be used to distinguish between consumer groups. The authors used a questionnaire to evaluate emotions, level of wine involvement, satisfaction and loyalty to wine compared to other beverages. Using an emotion-based cluster analysis from a sample of 1269 Spanish wine consumers, four groups were found namely "emotionally unattached", "negatives", "contented circumspect", and "wine lovers" (Calvo-Porral et al., 2020). The smallest group was "emotionally unattached", representing $\sim 15 \%$ of the participants with an age range predominantly between 18 and 30 years old. This group consumed wine several times a week, nevertheless they felt poorly attached or connected with wine. Emotionally unattached consumers were shown to experience the lowest ratings of emotions such as enthusiastic, and passionate (Calvo-Porral et al., 2020). Nevertheless, it is remarkable that these consumers have the habit of consuming wine regularly, probably as a result of their socio-cultural environment, since Rioja is a Spanish region where wine consumption is common in everyday meals. The cluster of "negative" consumers represented $\sim 29 \%$ of the total sample with a predominant age range of 18 to 40 years old and occasional consumption of wine "several times a month". This group reported negative emotions such as feeling aggressive, uncomfortable, bored, or feeling superior to other people when consuming wine. Despite the dominance of negative emotions, this group also experienced pleasant-high-arousing emotions above the average of the whole group, and scored low on pleasant-low-arousing emotions such as feeling interested, distinguished, appetizing, relaxed, or comfortable. The cluster of "contented circumspect" represented 20 percent of the sample population with an age range between 51 and 65 years old, and wine consumption frequency of several times a week. This group reported feeling lowarousal-pleasant emotions during wine consumption such as enthusiastic, interesting, relaxed, curious, and comfortable. Finally, the "wine lovers" group represented $\sim 43 \%$ of the sample population, with a predominant age range between 41 to 65 years old and wine consumption on a daily basis or several times a week. This group was characterized for experiencing pleasant and active emotions during wine consumption and used higher intensity ratings; terms such as feeling euphoric, funny, passionate, delighted, and happy were characteristic in "wine lovers". The authors suggested that this group could be more susceptible to marketing actions and that their high level of involvement and emotional responses require that wineries dedicate special attention about how to enhance their experience and strengthening emotional bonds with products. Overall, all the taster profiles were characterized for experiencing a majority of positive emotions, in agreement with the concept of hedonic asymmetry (King \& Meiselman, 2010). Nevertheless, it is important to point out that by design, the terms used in this study originated from the lexicon of Ferrarini et al. (2010) which already had a predefined majority of positive emotion options. Limitations of this study are that it was unclear if participants were drinking wine at the time that they were answering the questionnaire (at bars and restaurants), the volume of wine consumed prior to their participation, and if a specific type of wine was being considered to answer the questionnaire. Danner et al. (2020) classified consumer segments into Wine enthusiasts, Aspirants and No Frills using the Fine Wine Instrument developed by Johnson \& Bastian (2015). According to this classification, more intense positive emotions were reported by Wine enthusiasts followed by Aspirants and No Frills. This result was in agreement with the results from Calvo-Porral et al. (2020). Specifically, Wine enthusiasts experienced more intense emotions of calm, contented, enthusiastic, happy, optimistic, passionate, relaxed, and warm hearted in comparison with the other two groups (Danner et al., 2020). The authors also noted that Wine Enthusiasts enjoyed wine more than other profiles regardless of the context of consumption (Danner et al., 2020).

Coppin et al. (2021) characterized the emotions evoked by 8 wines (red and white) in 126 consumers with high and low levels of self-reported expertise (or involvement). Interestingly, the authors found that the number of emotions reported by both low and high experience consumers was not affected by tasting wines in a blind or informed setting. Moreover, no significant differences on the number of emotional terms were found between the levels of experience (Coppin et al., 2021). Differences between consumer groups and tasting conditions were found when evaluating the proportion of positive and negative emotional terms: at the blind tasting condition, both groups used predominantly positive emotion terms (50 to $80 \%$ ) to describe the wines. On the other hand, at the informed tasting condition the proportion of positive terms ranged from $\sim 46$ to $85 \%$. Sensitivity to the wine reputation -controlled by the information shown on the label- seemed to play a role to differentiate between taster's experience; experienced tasters used less positive emotional terms when they had a higher sensitivity to wine reputation, whereas low-experienced tasters behave in the opposite way. It is important to remark that $14 \%$ of the terms provided to tasters were negative, and any potential bias introduced by this unbalanced proportion was not taken into account. However, when looking only at the proportion of negative emotion terms, participants who received wine label information tended to have a higher proportion of negative feelings toward the wine (Coppin et al., 2021).

Beyond the classical approach of using self-reported ratings or scales of emotion, the use of emojis to characterize product involvement was successfully introduced by Jaeger, Lee, et al. (2018). The authors found that Chinese consumers with higher wine involvement used more emojis to describe French red wine, with smiling face with smiling eyes , thumbs up and red heart as the most recurrently used descriptors.

Differences between wine consumers of different nationalities have been addressed by Ristic et al. (2019) and (Silva et al., 2016). When comparing the conceptualization of wine using emotional terms, Silva et al. (2016) found that Portuguese consumers primarily felt more relaxed, pleased, loving, happy, comforted and calm, while Dutch consumers 
felt calm, loving, and relaxed. Interestingly, the emotional conceptualization of wine by both nationalities was very similar and no distinct emotions between nationalities were found (Silva et al., 2016). Ristic et al. (2019) provided a comprehensive comparison of Australian, UK and USA consumers in terms or several demographical variables and wine sensory attributes (primarily aromas). For example, Australian consumers showed higher liking of wines with a "pepper" aroma, contrasting with USA consumers, who considered this aroma as unacceptable. Another contrast between nationalities was found for level of education; Australian consumers with post-graduate degrees rated emotions higher than consumers with no tertiary degree, while the opposite was found for UK and USA consumers (Ristic et al., 2019).

When evaluating the gender effect, Mora et al. (2018) found that men produced higher emotion ratings that women, and that women scored higher ratings for joyful when consuming white wines. When evaluating wine aromas in terms of nationality and gender, "passionfruit" evoked more intense happy and nostalgic emotions in Australian and UK females and USA males (Ristic et al., 2019).

In terms of age, Ristic et al. (2019) found that younger wine consumers generally rated emotions higher than older age groups across all nationalities (Australian, USA, UK). Conversely, Mora et al. (2018) observed that older adults (> 55 years old, Spaniards) rated higher emotional terms such as happy, enthusiastic, joyful, pleasant, satisfied, and curious, compared to young adults. This discrepancy remarks the relevance of nationality when assessing demographical variables. Mora et al. (2021) deepened on the concept of consumer profiling by age segment using emotions to explore young consumers (18 to 35 years old) attitudes toward red wine sensory attributes. First, participants were asked to conceptualize their ideal red wine in terms of extrinsic (contextual) or intrinsic (flavor) attributes, and afterwards provided hedonic and emotional ratings evoked by different red wines. Both liking and emotional responses were useful to characterize the different qualities of wines and provided a way to identified that flavor was considered as the most important quality attribute, followed by price, and protected designation of origin (Mora et al., 2021).

The link between personality traits and emotions evoked by wine is another aspect of consumer profiles that was evaluated by Mora et al. (2019). Personality profiles were obtained by means of the Big Five Inventory questionnaire, which is a self-reported instrument designed to measure five dimensions of personality, namely openness, conscientiousness, extraversion, agreeableness, and neuroticism (John \& Srivastava, 1999). One of the main findings was that personality traits more than wine sample had a higher influence on emotions evoked by wine (Mora et al., 2019). Moreover, extraversion and neuroticism were the personality traits most closely aligned with emotions. Specifically, participants high in extraversion reacted more strongly to wines containing positive sensory attributes, while participants high in neuroticism rated higher negative emotions (Mora et al., 2019).

Taken together, these results provide substantial evidence that emotions can be used as a way to characterize diverse wine styles and that a single wine can evoke a dif- ferentiated emotional reaction in different consumer segments. Beyond the consumer profile aspects reviewed thus far, psychological variables related to learning and culture are known to modulate the experience of consuming foods and beverages and deserve further investigation (Levitan et al., 2014; Mizutani et al., 2012).

\section{Wine flavor molecules linked to emotions}

In the book Neuroenology (Shepherd, 2016, p. 168), a fundamental question is asked: "if pleasure is the main criterion for wine tasters, how do wine makers produce wines to satisfy this criterion?”. A simple answer to this question is to produce wine that have pleasant or emotional flavors. By controlling production variables related to vineyard management and winemaking techniques, viticulturists and winemakers are able to influence the composition and quantity of wine flavor molecules present in wines. It is flavor molecules that ultimately define intrinsic sensory attributes associated to specific regions, varietals, winemaking styles, etc., and many of these flavor molecules have been classified as positive or negative as a function of their effect in consumer acceptance. For example, off flavors, taints or faults such as cork-taint, animal character and oxidation are caused by chemical and microbiological degradation of wines, and have received particular attention due to their association with consumer rejection (Waterhouse et al., 2016, p. 149). On the other hand, pleasant aromas described as floral, citrus, and fruity are the result of grape varietal character and optimization of winemaking processes such as maceration, fermentation and ageing. Therefore, evaluating the capacity of different wine flavor molecules to evoke emotions is becoming an emerging alternative to characterize wine quality and to identify which sensory attributes contribute to create pleasurable experience for consumers.

Research manuscripts addressing the link between emotions and wine intrinsic flavor attributes are identified in Table 2. These references used emotion terms to characterize or differentiate wines from single varietals, wine styles (red, white, sparkling, etc.), and wines with specific sensory attributes, notably aromas.

Danner et al. (2017) showed how varietals such as Sauvignon Blanc evoked more intense positive emotions such as calm, contented, enthusiastic, happy, optimistic, passionate, and warm-hearted compared to Chardonnay and Riesling wines. While the authors did not establish a correlation between emotions and flavor attributes obtained by descriptive analysis, it could be hypothesized that the distinct flavor profiles of the varietal wines -mainly evaluated by aroma attributes in this research- are part of the primary factors influencing these results.

Jiang et al. (2017) used a single Cabernet Sauvignon red wine which was independently spiked with floral and green aromas (rose water, and isobutyl methoxypyrazine, IBMP) to evaluate their influence on evoked emotions. Overall, it was found that the intensity of emotions evoked by the wines with different aromas ranged from "not at all" to "slightly". This low emotional arousal was linked to the number of attributes evaluated (21 in total including emotions, pleasantness, and intensity). In the control and flo- 
ral-spiked wines, terms such as relaxed, happy, calm, warmhearted, and content, were rated higher than negative emotions; conversely, irritated, tense, and unfulfilled were rated higher in wines spiked with a IBMP (usually described as green pepper) (Jiang et al., 2017).

Mora et al. (2018) evaluated if emotional terms were able to distinguish between sensory attributes typically found in white, rose, and red Spanish wines. Using principal component analysis, they identified that emotional language related with positive emotions such as Joyful, pleasant, happy, enthusiastic, and warm, overlapping with aroma descriptors such as banana, apple, pineapple, and floral; conversely, negative emotions such as disgusted, aggressive, guilty, overlapped with sensory descriptors acid, clove, licorice and astringent. These findings were among the first to link specific emotional terms evoked by aroma, taste, and mouthfeel descriptors. With a similar approach, Ristic et al. (2019) evaluated the link between nine aroma descriptors and a list of emotions using the ScentMove ${ }^{\mathrm{TM}}$ scale. The following dominant emotions for wine aromas were identified: chocolate-happiness, lemon-energetic, strawberry-happiness, passionfruit-happiness, rose-happiness-romantic-relaxed, mintenergetic, confectionary-happiness-nostalgic, pepper-happiness-energetic, and barnyard-disgusted (Ristic et al., 2019). Emotion lexicons have also been used to characterize appellation of origin in Spanish, Italian, and Australian wines (Coste et al., 2018; Danner et al., 2020; Kustos et al., 2021; Mora et al., 2018; Sinesio et al., 2021).

Winemaking additives such as enological tannin and gums (xanthan, acacia, guar) are increasingly used by winemakers to adjust quality attributes such as astringency and the holistic perception of body. (Niimi et al., 2017) studied the effect of adding grape seed tannin and xanthan gum on 19 emotion attributes using the Australian Wine Evoked Emotions Lexicon (Danner et al., 2016). A white wine from Semillon was used as a base after treatment with activated carbon to decrease aroma intensity and allow tasters to concentrate on the manipulation of astringency by tannin, and viscosity by xanthan gum. Results showed that tannin additions had a significant effect on 11 emotions, which characterized by decreasing the intensity of positive emotions and increasing the intensity of negative emotions. Comparing the tannin addition to the control, calm, happy, relaxed, and warm hearted showed a large decrease of ratings, while irritated, panicky, tense and embarrassed had higher ratings. The addition of xanthan gum had no effect on emotions or liking of the wines. These results were the first to highlight emotional profiles linked to enological additives and suggest that the astringency produced by enological tannin is a driver for emotional responses in white wine, whereas viscosity is not. More research using other viscosity-related additives is needed to evaluate their effect on emotions.

The influence of oak flavors was evaluated by Silva et al. (2018) by comparing Portuguese white wines produced in stainless steel vats and aged in oak barrels. Remarkably, the authors used Temporal Dominance of Emotions and Temporal Dominance of Sensations (flavor attributes) as a strategy to characterize the evolution of the consumer experience during a sequence of three sips. One of the main findings was that dominant flavors changed continuously, while a set of three emotions (relaxed, pleased, comforted) dominated the tasting experience (Silva et al., 2018). Comforted was identified as the dominant emotions in oaked white wines during the middle and final stages of consumption.

Beyond wine flavor molecules, the taster's genetic variations of sensory cells such as taste receptors, olfactory sensory neurons, amongst others are known to play an important role in how consumers perceive flavor molecules (Behrens et al., 2013; Jaeger et al., 2013). The fact that vision, smell, and taste can be integrated at specific regions of the human brain explains many of the learned associations and expectations that are evoked by the experience of consuming food and beverages (De Araujo et al., 2003; Krishna, 2012; Prescott, 2015; Shankar et al., 2010). Therefore, including biological (genetic) traits might be a way to deepen our understanding the variations in subjective perception of flavor molecules present in wine.

\section{Emotions as part of wine tasting protocols}

Classic wine tasting protocols used by professionals, and typically practiced in winery tasting-rooms, feature a sequence of steps that include visual, olfactory, taste, and mouthfeel attributes that are typically rated using scales. Nevertheless, including emotional attributes in the traditional process may be a way to expand our understanding of the wine quality. Loureiro et al. (2016) addressed this challenge by embedding emotional terms within the steps of the tasting protocol from the International Organization of Vine and Wine. The authors recommended starting wine appraisal with the nose (olfactory-only) attributes and included "Initial impression" and "expectations for the mouth" as emotional attributes. In the second step, the mouth attributes feature "Relation to smell" which aims the capture the congruency of expectations raised by Nose attributes. The final step requires an overall emotional attribute that rates wines using a valence scale ranging from disagreeable to exciting. As can be seen, expectations and congruency were considered by the authors as part of the emotional attributes of wine. While the link between sensory expectations/congruency and emotions may require a more in-depth justification, the concept of embedding emotional attributes to classic tasting protocols is an innovative approach that can expand our understanding of hedonic processes in wine tasters.

\section{Conclusions and future perspectives}

The primary objective of this review was to highlight the role of emotions as a fundamental aspect that defines wine quality. Reports from the last ten years have shown how wine flavor molecules, tasting environments, wine label information and demographical aspects such as age, gender, and taster experience are part of the variables defining the emotional response from tasters to wines.

Explicit measurements such as questionnaires and ratings of predefined terms have been the benchmark methodology to investigate emotions evoked by intrinsic and extrinsic wine attributes. By using these techniques, 72 emotion terms have been identified and used to describe wine, where 30 are unique to specific studies or populations. Most of these emotional terms have been obtained 
from predominantly Caucasian populations (Italian, Spanish, Swiss, and Australian consumers), and therefore incorporating multicultural approaches would be beneficial. Despite the recommendation to avoid having too many terms in emotional questionnaires (Meiselman, 2015), the optimal number of terms is ill defined and remains to be defined by future research.

Despite the emergence of implicit measurements to measure emotions, such as facial expressions, heart rate, respiration rate, and brain activity, these techniques remain to be applied to wine studies. The fact that implicit measurements are produced automatically would allow to override cognitive biases commonly found with traditional methods. Therefore, a synergy between both explicit and implicit measurements is likely to provide a more robust basis to characterize emotions.

The lack of reference stimuli to define emotions is identified as one of the major challenges ahead. Further, studies involving comparisons between different beverages (wine styles, beer, hard-seltzers) and food would also be beneficial to reveal areas of opportunity with specific consumer populations.
Given the primary role of flavor in evoking emotions, future studies should expand on the emotional qualities of molecules responsible for wine aromas, taste (sweet, acid, bitter), mouthfeel (astringency, body, etc.), and defects or taints. This knowledge can provide additional criteria for winemakers to create pleasurable wine experiences for consumers.

\section{Acknowledgements}

The implicit measurement section of this manuscript was inspired by the MSc thesis of Robert Herrell and Kori Munk. I am grateful to the California State University-Agricultural Research Institute, the Industry Advisory Board of the Department of Viticulture and Enology, and Treasury Wine States for supporting projects 2020-021, 2018-19, 2018-022.

Submitted: July 22, 2021 PDT, Accepted: December 10, 2021 PDT 


\section{References}

Aaronson, P. I. (1999). The cardiovascular system at a glance. Blackwell Science.

Agrafioti, F., Hatzinakos, D., \& Anderson, A. K. (2012). ECG Pattern Analysis for Emotion Detection. IEEE Transactions on Affective Computing, 3(1), 102-115. ht tps://doi.org/10.1109/t-affc.2011.28

Alaoui-Ismaili, O., Vernet-Maury, E., Dittmar, A., Delhomme, G., \& Chanel, J. (1997). Odor Hedonics: Connection with Emotional Response Estimated by Autonomic Parameters. Oxford University Press.

Ares, G., Bruzzone, F., Vidal, L., Cadena, R. S., Giménez, A., Pineau, B., Paisley, A. G., Hunter, D. C., \& Jaeger, S. R. (2014). Evaluation of a rating-based variant of check-all-that-apply questions: Rate-all-that-apply (RATA). Food Quality and Preference, 36, 87-95. http s://doi.org/10.1016/j.foodqual.2014.03.006

Bailey, R. L. (2016). Modern foraging: Presence of food and energy density influence motivational processing of food advertisements. Appetite, 107, 568-574. http s://doi.org/10.1016/j.appet.2016.09.001

Behrens, M., Gunn, H. C., Ramos, P. C. M., Meyerhof, W., \& Wooding, S. P. (2013). Genetic, functional, and phenotypic diversity in TAS2R38-mediated bitter taste perception. Chemical Senses, 38(6), 475-484. htt ps://doi.org/10.1093/chemse/bjt016

Bensafi, M. (2002). Autonomic Nervous system responses to odours: The role of pleasantness and arousal. Chemical Senses, 27(8), 703-709. https://do i.org/10.1093/chemse/27.8.703

Beyts, C., Chaya, C., Dehrmann, F., James, S., Smart, K., \& Hort, J. (2017). A comparison of self-reported emotional and implicit responses to aromas in beer. Food Quality and Preference, 59, 68-80. https://doi.or g/10.1016/i.foodqual.2017.02.006

Braithwaite, J. J., Watson, D. G., Jones, R., \& Rowe, M. (2013). A guide for analysing electrodermal activity (EDA) \& skin conductance responses (SCRs) for psychological experiments. Psychophysiology, 49(1), 1017-1034.

Cabiddu, F. (2007). Comportamento del consumatore e Scelte Strategiche delle Imprese: Il Ruolo del Contesto (Vol. 499). FrancoAngeli.

Calvo-Porral, C., Lévy-Mangin, J.-P., \& Ruiz-Vega, A. (2020). An emotion-based typology of wine consumers. Food Quality and Preference, 79. https://do i.org/10.1016/j.foodqual.2019.103777

Calvo-Porral, C., Ruiz-Vega, A., \& Levy-Mangin, J.-P. (2018). Does product involvement influence how emotions drive satisfaction?: An approach through the Theory of Hedonic Asymmetry. European Research on Management and Business Economics, 24(3), 130-136. https://doi.org/10.1016/j.iedeen.2018.06.00 1

Calvo-Porral, C., Ruiz-Vega, A., \& Lévy-Mangin, J.-P. (2019). The influence of consumer involvement in wine consumption-elicited emotions. Journal of International Food \& Agribusiness Marketing, 31(2), 128-149. https://doi.org/10.1080/08974438.2018.148 $\underline{2587}$
Charland, L. (2014). Emotion, phylosophical perspectives. In T. Bayne, A. Cleeremans, \& P. Wilken (Eds.), The Oxford Companion to Consciousness (pp. 259-262). OUP Oxford.

Combris, P., Bazoche, P., Giraud-Héraud, E., \& Issanchou, S. (2009). Food choices: What do we learn from combining sensory and economic experiments? Food Quality and Preference, 20(8), 550-557.

Coppin, G., Audrin, C., Monseau, C., \& Deneulin, P. (2021). Is knowledge emotion? The subjective emotional responses to wines depend on level of selfreported expertise and sensitivity to key information about the wine. Food Research International, 142, 110192. https://doi.org/10.1016/i.foodres.2021.11019 2

Coste, A., Souse, P., \& Malfeito-Ferreira, M. (2018). Wine tasting based on emotional responses: An expedite approach to distinguish between warm and cool climate dry red wine styles. Food Research International, 106, 11-21. https://doi.org/10.1016/i.fo odres.2017.12.039

Croy, I., Olgun, S., \& Joraschky, P. (2011). Basic emotions elicited by odors and pictures. Emotion, 11(6), 1331.

Damasio, A. (2001). Fundamental feelings. Nature, 413(6858), 781-781. https://doi.org/10.1038/3510166 $\underline{9}$

Danner, L., Crump, A. M., Croker, A., Gambetta, J. M., Johnson, T. E., \& Bastian, S. E. P. (2018). Comparison of rate-all-that-apply and descriptive analysis for the sensory profiling of wine. American Journal of Enology and Viticulture, 69(1), 12-21. https://doi.org/10.5344/ ajev.2017.17052

Danner, L., Haindl, S., Joechl, M., \& Duerrschmid, K. (2014). Facial expressions and autonomous nervous system responses elicited by tasting different juices. Food Research International, 64, 81-90. https://doi.or $\mathrm{g} / 10.1016 /$ i.foodres.2014.06.003

Danner, L., Johnson, T. E., Ristic, R., Meiselman, H. L., \& Bastian, S. E. P. (2017). "I like the sound of that!" Wine descriptions influence consumers' expectations, liking, emotions and willingness to pay for Australian white wines. Food Research International, 99(Pt 1), 263-274. https://doi.org/10.1016/j.foodres.2017.05.01 $\underline{9}$

Danner, L., Johnson, T. E., Ristic, R., Meiselman, H. L., \& Bastian, S. E. P. (2020). Consumption Context Effects on Fine Wine Consumer Segments' Liking and Emotions. Foods, 9(12), 1798. https://doi.org/10.3390/ foods 9121798

Danner, L., Ristic, R., Johnson, T. E., Meiselman, H. L., Hoek, A. C., Jeffery, D. W., \& Bastian, S. E. P. (2016). Context and wine quality effects on consumers' mood, emotions, liking and willingness to pay for Australian Shiraz wines. Food Research International, 89(Pt 1), 254-265. https://doi.org/10.1016/i.foodres.2 $\underline{016.08 .006}$ 
De Araujo, I. E. T., Rolls, E. T., Kringelbach, M. L., McGlone, F., \& Phillips, N. (2003). Taste-olfactory convergence, and the representation of the pleasantness of flavour, in the human brain. European Journal of Neuroscience, 18(7), 2059-2068.

De Martino, B., Kumaran, D., Seymour, B., \& Dolan, R. J. (2006). Frames, Biases, and Rational Decision-Making in the Human Brain. Science, 313(5787), 684-687. http s://doi.org/10.1126/science.1128356

de Wijk, R. A., \& Boesveldt, S. (2016). Responses of the Autonomic Nervous System to Flavors. In B. Piqueras-Fiszman \& C. Spence (Eds.), Multisensory Flavor Perception: From Fundamental Neuroscience through to the Marketplace (pp. 249-268). Woodhead Publishing.

De Wijk, R. A., \& Boesveldt, S. (2016). Responses of the Autonomic Nervous System to Flavors. In B. Piqueras-Fiszman \& C. Spence (Eds.), Multisensory Flavor Perception: From Fundamental Neuroscience through to the Marketplace (pp. 249-268). Woodhead Publishing.

de Wijk, R. A., He, W., Mensink, M. G., Verhoeven, R. H., \& de Graaf, C. (2014). ANS responses and facial expressions differentiate between the taste of commercial breakfast drinks. PLoS One, 9(4), e93823. https://doi.org/10.1371/journal.pone.0093823

De Wijk, R. A., Kooijman, V., Verhoeven, R. H. G., Holthuysen, N. T. E., \& De Graaf, C. (2012). Autonomic nervous system responses on and facial expressions to the sight, smell, and taste of liked and disliked foods. Food Quality and Preference, 26(2), 196-203. https://doi.org/10.1016/j.foodqual.2012.0 $\underline{4.015}$

de Wijk, R. A., Kooijman, V., Verhoeven, R. H. G., Holthuysen, N. T. E., \& de Graaf, C. (2012). Autonomic nervous system responses on and facial expressions to the sight, smell, and taste of liked and disliked foods. Food Quality and Preference, 26(2), 196-203. https://doi.org/10.1016/i.foodqual.2012.0 $\underline{4.015}$

Deco, G., Rolls, E. T., Albantakis, L., \& Romo, R. (2013). Brain mechanisms for perceptual and reward-related decision-making. Progress in Neurobiology, 103(0), 194-213. https://doi.org/10.1016/j.pneurobio.2012.0 1.010

Delplanque, S., Grandjean, D., Chrea, C., Coppin, G., Aymard, L., Cayeux, I., Margot, C., Velazco, M. I., Sander, D., \& Scherer, K. R. (2009). Sequential unfolding of novelty and pleasantness appraisals of odors: Evidence from facial electromyography and autonomic reactions. Emotion, 9(3), 316-328. http s://doi.org/10.1037/a0015369

Desmet, P. M., \& Schifferstein, H. N. (2008). Sources of positive and negative emotions in food experience. Appetite, 50(2-3), 290-301. https://doi.org/10.1016/ j.appet.2007.08.003

Ekman, P. (1992). An argument for basic emotions. Cognition and Emotion, 6(3-4), 169-200. https://doi.o $\mathrm{rg} / 10.1080 / 02699939208411068$

Ekman, P., \& Friesen, W. V. (1978). Manual for the facial action coding system. Consulting Psychologists Press.
Ekman, P., Levenson, R., \& Friesen, W. (1983). Autonomic nervous system activity distinguishes among emotions. Science, 221(4616), 1208-1210. http s://doi.org/10.1126/science.6612338

Ellsworth, P. C., \& Scherer, K. R. (2003). Appraisal processes in emotion. In Handbook of Affective Sciences (pp. 572-595). Oxford University Press.

Ferrarini, R., Carbognin, C., Casarotti, E. M., Nicolis, E., Nencini, A., \& Meneghini, A. M. (2010). The emotional response to wine consumption. Food Quality and Preference, 21(7), 720-725. https://doi.or g/10.1016/j.foodqual.2010.06.004

Frost, R., Quiñones, I., Veldhuizen, M., Alava, J.-I., Small, D., \& Carreiras, M. (2015). What can the brain teach us about winemaking? An fMRI study of alcohol level preferences. PLoS ONE, 10(3), e0119220. http s://doi.org/10.1371/journal.pone.0119220

Giboreau, A., \& Meiselman, H. L. (2018). Emotions before and after a meal in a natural eating situation. Food Quality and Preference, 65, 191-193. https://do i.org/10.1016/i.foodqual.2017.10.016

Gold, J. I., \& Shadlen, M. N. (2007). The neural basis of decision making. Annual Review of Neuroscience, 30(1), 535-574. https://doi.org/10.1146/annurev.neur o.29.051605.113038

Grabenhorst, F., \& Rolls, E. T. (2011). Value, pleasure and choice in the ventral prefrontal cortex. Trends in Cognitive Sciences, 15(2), 56-67. https://doi.org/10.10 16/i.tics.2010.12.004

Grabenhorst, F., Rolls, E. T., Margot, C., Da Silva, M. A. A. P., \& Velazco, M. I. (2007). How pleasant and unpleasant stimuli combine in different brain regions: Odor mixtures. Journal of Neuroscience, 27(49), 13532-13540. https://doi.org/10.1523/ineuros ci.3337-07.2007

He, W., Boesveldt, S., De Graaf, C., \& De Wijk, R. A. (2014). Dynamics of autonomic nervous system responses and facial expressions to odors. Frontiers in Psychology, 5. https://doi.org/10.3389/fpsyg.2014.001 $\underline{10}$

He, W., Boesveldt, S., De Graaf, C., \& De Wijk, R. A. (2016). The relation between continuous and discrete emotional responses to food odors with facial expressions and non-verbal reports. Food Quality and Preference, 48, 130-137. https://doi.org/10.1016/i.food qual.2015.09.003

He, W., Boesveldt, S., Delplanque, S., de Graaf, C., \& de Wijk, R. A. (2017). Sensory-specific satiety: Added insights from autonomic nervous system responses and facial expressions. Physiology \& Behavior, 170, 12-18. https://doi.org/10.1016/j.physbeh.2016.12.012

He, W., De Wijk, R. A., De Graaf, C., \& Boesveldt, S. (2016). Implicit and Explicit Measurements of Affective Responses to Food Odors. Chemical Senses, 41(8), 661-668. https://doi.org/10.1093/chemse/bjw0 $\underline{68}$

Horska, E., Bercik, J., Krasnodebski, A., Matysik-Pejas, R., \& Bakayova, H. (2016). Innovative approaches to examining consumer preferences when choosing wines. Agricultural Economics (Zemědělská Ekonomika), 62(3), 124-133. https://doi.org/10.17221/ 290/2015-agricecon 
Hutcherson, C. A., Plassmann, H., Gross, J. J., \& Rangel, A. (2012). Cognitive regulation during decisionmaking shifts behavioral control between ventromedial and dorsolateral prefrontal value systems. Journal of Neuroscience, 32(39), 13543-13554. https://doi.org/10.1523/jneurosci.638 7-11.2012

Jackson, R. S. (2009). Wine Tasting: A Professional Handbook (2nd ed.). Academic Press.

Jaeger, S. R., Lee, P. Y., \& Ares, G. (2018). Product involvement and consumer food-elicited emotional associations: Insights from emoji questionnaires. Food Research International, 106, 999-1011. https://do i.org/10.1016/j.foodres.2018.01.024

Jaeger, S. R., McRae, J. F., Bava, C. M., Beresford, M. K., Hunter, D., Jia, Y., Chheang, S. L., Jin, D., Peng, M., Gamble, J. C., Atkinson, K. R., Axten, L. G., Paisley, A. G., Tooman, L., Pineau, B., Rouse, S. A., \& Newcomb, R. D. (2013). A Mendelian trait for olfactory sensitivity affects odor experience and food selection. Current Biology, 23(16), 1601-1605. https://doi.org/1 0.1016/j.cub.2013.07.030

Jaeger, S. R., Roigard, C. M., \& Ares, G. (2018). Measuring consumers' product associations with emoji and emotion word questionnaires: case studies with tasted foods and written stimuli. Food Research International, 111, 732-747. https://doi.org/10.1016/ j.foodres.2018.04.010

Jaeger, S. R., Spinelli, S., Ares, G., \& Monteleone, E. (2018). Linking product-elicited emotional associations and sensory perceptions through a circumplex model based on valence and arousal: Five consumer studies. Food Research International, 109, 626-640. https://doi.org/10.1016/j.foodres.2018.04.06 $\underline{3}$

Jiang, W., Niimi, J., Ristic, R., \& Bastian, S. E. P. (2017). Effects of immersive context and wine flavor on consumer wine flavor perception and elicited emotions. American Journal of Enology and Viticulture, 68(1), 1-10. https://doi.org/10.5344/ajev.2016.16056

John, O. P., \& Srivastava, S. (1999). The Big-Five trait taxonomy: History, measurement, and theoretical perspectives (Vol. 2). University of California Berkeley.

Johnson, T. E., \& Bastian, S. E. P. (2015). A fine wine instrument - an alternative for segmenting the Australian wine market. International Journal of Wine Business Research, 27(3), 182-202. https://doi.org/1 0.1108/ijwbr-04-2014-0020

Kaneko, D., Toet, A., Brouwer, A.-M., Kallen, V., \& van Erp, J. B. F. (2018). Methods for Evaluating Emotions Evoked by Food Experiences: A Literature Review. Frontiers in Psychology, 9(911). https://doi.org/10.338 9/fpsyg.2018.00911

King, S. C., \& Meiselman, H. L. (2010). Development of a method to measure consumer emotions associated with foods. Food Quality and Preference, 21(2), 168-177. https://doi.org/10.1016/i.foodqual.2009.02.0 $\underline{05}$

King, S. C., Meiselman, H. L., \& Thomas Carr, B. (2013). Measuring emotions associated with foods: Important elements of questionnaire and test design. Food Quality and Preference, 28(1), 8-16. https://doi.org/1 0.1016/j.foodqual.2012.08.007
Kreibig, S. D. (2010). Autonomic nervous system activity in emotion: a review. Biological Psychology, 84(3), 394-421. https://doi.org/10.1016/j.biopsycho.2010.0 $\underline{3.010}$

Kringelbach, M. L. (2005). The human orbitofrontal cortex: Linking reward to hedonic experience. Nature Reviews Neuroscience, 6(9), 691-702. https://doi.org/1 $\underline{0.1038 / \mathrm{nrn} 1747}$

Kringelbach, M. L., Stein, A., \& van Hartevelt, T. J. (2012). The functional human neuroanatomy of food pleasure cycles. Physiology \& Behavior, 106(3), 307-316. https://doi.org/10.1016/j.physbeh.2012.03.0 $\underline{23}$

Krishna, A. (2012). An integrative review of sensory marketing: Engaging the senses to affect perception, judgment and behavior. Journal of Consumer Psychology, 22(3), 332-351.

Kuroda, K., Inoue, N., Ito, Y., Kubota, K., Sugimoto, A., Kakuda, T., \& Fushiki, T. (2005). Sedative effects of the jasmine tea odor and (R)-(-)-linalool, one of its major odor components, on autonomic nerve activity and mood states. European Journal of Applied Physiology, 95(2-3), 107-114. https://doi.org/10.1007/ s00421-005-1402-8

Kustos, M., Goodman, S., Jeffery, D. W., \& Bastian, S. E. P. (2021). Appropriate food and wine pairings and wine provenance information: Potential tools for developing memorable dining experiences. Food Quality and Preference, 94. https://doi.org/10.1016/j.fo odqual.2021.104297

Lacey, B. C., \& Lacey, J. I. (1978). Two-way communication between the heart and the brain: Significance of time within the cardiac cycle. American Psychologist, 33(2), 99-113. https://doi.org/ 10.1037/0003-066X.33.2.99

Lagast, S., Gellynck, X., Schouteten, J. J., De Herdt, V., \& De Steur, H. (2017). Consumers' emotions elicited by food: A systematic review of explicit and implicit methods. Trends in Food Science \& Technology, 69, 172-189. https://doi.org/10.1016/i.tifs.2017.09.006

Larsen, J. T., Norris, C. J., \& Cacioppo, J. T. (2003). Effects of positive and negative affect on electromyographic activity over zygomaticus major and corrugator supercilii. Psychophysiology, 40(5), 776-785. https://doi.org/10.1111/1469-8986.00078

Lawless, H. T. (1989). Logarithmic transformation of magnitude estimation data and comparisons of scaling methods. Journal of Sensory Studies, 4(2), 75-86. https://doi.org/10.1111/j.1745-459x.1989.tb00 459.x

Lawless, H. T., \& Heymann, H. (2010). Sensory evaluation of food: principles and practices (Vol. 5999). Springer Science \& Business Media.

Lenzen, M. (2005). Feeling our emotions. Scientific American. https://www.scientificamerican.com/articl e/feeling-our-emotions/

Levitan, C. A., Ren, J., Woods, A. T., Boesveldt, S., Chan, J. S., McKenzie, K. J., Dodson, M., Levin, J. A., Leong, C. X., \& van den Bosch, J. J. (2014). Cross-cultural color-odor associations. PLoS ONE, 9(7), e101651. htt ps://doi.org/10.1371/journal.pone.0101651 
Lewinski, P., den Uyl, T. M., \& Butler, C. (2014). Automated facial coding: validation of basic emotions and FACS AUs in FaceReader. Journal of Neuroscience, Psychology, and Economics, 7(4), 227.

Licon, C. C., Manesse, C., Dantec, M., Fournel, A., \& Bensafi, M. (2018). Pleasantness and trigeminal sensations as salient dimensions in organizing the semantic and physiological spaces of odors. Scientific Reports, 8(1), 8444. https://doi.org/10.1038/s41598-01 8-26510-5

Loureiro, V., Brasil, R., \& Malfeito-Ferreira, M. (2016). A new wine tasting approach based on emotional responses to rapidly recognize classic european wine styles. Beverages, 2(1). https://doi.org/10.3390/bevera ges2010006

Meilgaard, M. C., Civille, G., \& Carr, B. (2007). Sensory Evaluation Techniques (4th ed.). CRC Press.

Meilgaard, M. C., Civille, G. V., \& Carr, B. T. (2015). Sensory Evaluation Techniques (5th ed.). CRC Press.

Meilgaard, M. C., Civille, G. V., \& Carr, B. T. (2016). Sensory evaluation techniques.

Meiselman, H. L. (2015). A review of the current state of emotion research in product development. Food Research International, 76, 192-199. https://doi.org/1 0.1016/j.foodres.2015.04.015

Meiselman, H. L. (2021). The (gradual) development of emotion measurement for food. Current Opinion in Food Science, 40, 187-191. https://doi.org/10.1016/j.c ofs.2021.03.017

Mizutani, N., Dan, I., Kyutoku, Y., Tsuzuki, D., Clowney, L., Kusakabe, Y., Okamoto, M., \& Yamanaka, T. (2012). Package images modulate flavors in memory: Incidental learning of fruit juice flavors. Food Quality and Preference, 24(1), 92-98.

Mora, M., Dupas de Matos, A., Fernandez-Ruiz, V., Briz, T., \& Chaya, C. (2020). Comparison of methods to develop an emotional lexicon of wine: Conventional vs rapid-method approach. Food Quality and Preference, 83. https://doi.org/10.1016/i.foodqual.202 $\underline{0.103920}$

Mora, M., Dupas de Matos, A., Vázquez-Araújo, L., Puente, V., Hernando, J., \& Chaya, C. (2021). Exploring young consumers' attitudes and emotions to sensory and physicochemical properties of different red wines. Food Research International, 143, 110303-110303. https://doi.org/10.1016/j.foodres.202 1.110303

Mora, M., Urdaneta, E., \& Chaya, C. (2018). Emotional response to wine: Sensory properties, age and gender as drivers of consumers' preferences. Food Quality and Preference, 66, 19-28. https://doi.org/10.1016/i.foodq ual.2017.12.015

Mora, M., Urdaneta, E., \& Chaya, C. (2019). Effect of personality on the emotional response elicited by wines. Food Quality and Preference, 76, 39-46. http s://doi.org/10.1016/j.foodqual.2019.03.015

Nath, E. C., Cannon, P. R., \& Philipp, M. C. (2020). Coacting strangers but not friends influence subjective liking and facial affective responses to food stimuli. Food Quality and Preference, 82. https://doi.org/10.101 6/i.foodqual.2019.103865
Neta, M., Norris, C. J., \& Whalen, P. J. (2009). Corrugator muscle responses are associated with individual differences in positivity-negativity bias. Emotion, 9(5), 640-648. https://doi.org/10.1037/a0016 $\underline{819}$

Neuman, D., \& Adolphs, R. (2014). Emotion, implicit. In T. Bayne, A. Cleeremans, \& P. Wilken (Eds.), The Oxford Companion to Consciousness (pp. 257-258). OUP Oxford.

Niimi, J., Danner, L., Li, L., Bossan, H., \& Bastian, S. E. P. (2017). Wine consumers' subjective responses to wine mouthfeel and understanding of wine body. Food Research International, 99(Pt 1), 115-122. http s://doi.org/10.1016/j.foodres.2017.05.015

OIV. (2015). Review document on sensory analysis of wine. https://www.oiv.int/public/medias/3307/review-on-se nsory-analysis-of-wine.pdf

Parr, W. V. (2018). Demystifying wine tasting: Cognitive psychology's contribution. Food Research International, 124, 230-233. https://doi.org/10.1016/ j.foodres.2018.03.050

Pazart, L., Comte, A., Magnin, E., Millot, J.-L., \& Moulin, T. (2014). An fMRI study on the influence of sommeliers' expertise on the integration of flavor. Frontiers in Behavioral Neuroscience, 8, 358. https://do i.org/10.3389/fnbeh.2014.00358

Plassmann, H., O’Doherty, J., Shiv, B., \& Rangel, A. (2008). Marketing actions can modulate neural representations of experienced pleasantness. Proceedings of the National Academy of Sciences of the United States of America, 105(3), 1050-1054. http://w ww.scopus.com/inward/record.url?eid=2-s2.0-389491 99461 \&partnerID $=40 \&$ md5=9ed $1 \mathrm{ae} 8 \mathrm{ddfb} 112 \mathrm{e} 294 \mathrm{bfe}$ 9957ef5ddb1

Platania, M., Platania, S., \& Santisi, G. (2016). Entertainment marketing, experiential consumption and consumer behavior: the determinant of choice of wine in the store. Wine Economics and Policy, 5(2), 87-95. https://doi.org/10.1016/j.wep.2016.10.001

Posner, J., Russell, J. A., \& Peterson, B. S. (2005). The circumplex model of affect: An integrative approach to affective neuroscience, cognitive development, and psychopathology. Development and Psychopathology, 17(3). https://doi.org/10.1017/s0954579405050340

Prescott, J. (2015). Multisensory processes in flavour perception and their influence on food choice. Current Opinion in Food Science, 3, 47-52. https://doi.org/10.1 016/j.cofs.2015.02.007

Rajesh, K. M., \& Naveenkumar, M. (2016). A robust method for face recognition and face emotion detection system using support vector machines. 2016 International Conference on Electrical, Electronics, Communication, Computer and Optimization Techniques (ICEECCOT), 1-5. https://doi.org/10.1109/ ICEECCOT.2016.7955175

Ristic, R., Danner, L., Johnson, T. E., Meiselman, H. L., Hoek, A. C., Jiranek, V., \& Bastian, S. E. P. (2019). Wine-related aromas for different seasons and occasions: Hedonic and emotional responses of wine consumers from Australia, UK and USA. Food Quality and Preference, 71, 250-260. https://doi.org/10.1016/ j.foodqual.2018.07.011 
Rolls, E. T. (2015). Taste, olfactory, and food reward value processing in the brain. Progress in Neurobiology, 127-128, 64-90. https://doi.org/10.101 6/i.pneurobio.2015.03.002

Rolls, E. T., \& Baylis, L. L. (1994). Gustatory, olfactory, and visual convergence within the primate orbitofrontal cortex. Journal of Neuroscience, 14(9), 5437-5452. https://doi.org/10.1523/ineurosci.14-09-0 5437.1994

Rolls, E. T., Grabenhorst, F., Margot, C., da Silva, M. A., \& Velazco, M. I. (2008). Selective attention to affective value alters how the brain processes olfactory stimuli. Journal of Cognitive Neuroscience, 20(10), 1815-1826. https://doi.org/10.1162/jocn.200 $\underline{8.20128}$

Russell, J. A. (1980). A circumplex model of affect. Journal of Personality and Social Psychology, 39(6), 1161.

Sander, D. (2013). Models of emotion: the affective neuroscience approach. In J. Armony \& P. Vuilleumier (Eds.), The Cambridge Handbook of Human Affective Neuroscience. Cambridge University Press.

Santisi, G., \& Platania, S. (2014). Il rapporto tra il consumatore e il mass market brand: la determinante di scelta del Centro Commerciale. Micro \& Macro Marketing, 23(3), 461-478.

Sato, W., Yoshikawa, S., \& Fushiki, T. (2021). Facial EMG activity is associated with hedonic experiences but not nutritional values while viewing food images. Nutrients, 13(1), 11.

Shankar, M. U., Levitan, C. A., \& Spence, C. (2010). Grape expectations: The role of cognitive influences in color-flavor interactions. Consciousness and Cognition, 19(1), 380-390. https://doi.org/10.1016/j.c oncog.2009.08.008

Shepherd, G. M. (2006). Smell images and the flavour system in the human brain. Nature, 444(7117), 316-321.

Shepherd, G. M. (2015). Neuroenology: how the brain creates the taste of wine. Flavour, 4(1). https://doi.or $\mathrm{g} / 10.1186 / \mathrm{s} 13411-014-0030-9$

Shepherd, G. M. (2016). Neuroenology. Columbia University Press.

Silva, A. P., Jager, G., Van Bommel, R., Van Zyl, H., Voss, H.-P., Hogg, T., Pintado, M., \& De Graaf, C. (2016). Functional or emotional? How Dutch and Portuguese conceptualise beer, wine and non-alcoholic beer consumption. Food Quality and Preference, 49, 54-65. https://doi.org/10.1016/j.foodqual.2015.11.007
Silva, A. P., Voss, H. P., Zyl, van H., Hogg, T., Graaf, de C., Pintado, M., \& Jager, G. (2018). Temporal dominance of sensations, emotions, and temporal liking measured in a bar for two similar wines using a multi-sip approach. Journal of Sensory Studies, 33(5), e12459-n/a. https://doi.org/10.1111/joss.12459

Sinesio, F., Moneta, E., Di Marzo, S., Zoboli, G. P., \& Abbà, S. (2021). Influence of wine traits and context on liking, intention to consume, wine-evoked emotions and perceived sensory sensations. Food Quality and Preference, 93, 104268. https://doi.org/1 $\underline{0.1016 / \text { i.foodqual.2021.104268 }}$

Small, D. M. (2012). Flavor is in the brain. Physiology \& Behavior, 107(4), 540-552. https://doi.org/10.1016/j.p hysbeh.2012.04.011

Small, D. M., Veldhuizen, M. G., \& Green, B. (2012). Sensory Neuroscience: Taste Responses in Primary Olfactory Cortex. Current Biology, 23(4), R157-R159. https://doi.org/10.1016/i.cub.2012.12.036

Spence, C. (2015). Multisensory Flavor Perception. Cell, 161(1), 24-35. https://doi.org/10.1016/i.cell.2015.03.0 $\underline{07}$

Stern, R. M., Ray, W. J., \& Quigley, K. S. (2000). Psychophysiological Recording. Oxford University Press.

Stockli, S., Schulte-Mecklenbeck, M., Borer, S., \& Samson, A. C. (2018). Facial expression analysis with AFFDEX and FACET: A validation study. Behav Res Methods, 50(4), 1446-1460. https://doi.org/10.3758/s 13428-017-0996-1

Van Boxtel, A. (2010). Facial EMG as a tool for inferring affective states. Proceedings of Measuring Behavior, 104-108.

Van der Laan, L. N., De Ridder, D. T. D., Viergever, M. A., \& Smeets, P. A. M. (2011). The first taste is always with the eyes: A meta-analysis on the neural correlates of processing visual food cues. NeuroImage, 55(1), 296-303. https://doi.org/10.1016/j.neuroimag e.2010.11.055

Walker, W. R., Skowronski, J. J., \& Thompson, C. P. (2003). Life is pleasant-and memory helps to keep it that way! Review of General Psychology, 7(2), 203-210. https://doi.org/10.1037/1089-2680.7.2.203

Waterhouse, A. L., Sacks, G. L., \& Jeffery, D. W. (2016). Understanding Wine Chemistry. John Wiley \& Sons.

Wolf, K., Mass, R., Ingenbleek, T., Kiefer, F., Naber, D., \& Wiedemann, K. (2005). The facial pattern of disgust, appetence, excited joy and relaxed joy: An improved facial EMG study. Scandinavian Journal of Psychology, 46(5), 403-409. https://doi.org/10.1111/ j.1467-9450.2005.00471.x 